\title{
O efeito do Programa Territorial nas relações sociais dos agricultores familiares do Território da Cidadania do Vale do Rio Vermelho, em Goiás, Brasil
}

\author{
The effects of the Territorial Policy on social relationships of family farmers in the \\ Vale do Rio Vermelho Citzenship Territory, in Goiás, Brazil
}

\section{El efecto del Programa Territorial en las relaciones sociales de los campesinos en el Territorio de la Ciudadanía del Vale do Rio Vermelho, en Goiás, Brésil}

\author{
Ricardo de Siqueira Camargo* \\ (rsc3452@gmail.com) \\ Gabriel Medina* \\ (gabriel.silva.medina@gmail.com)
}

L'effet du Programme Territorial dans les relations sociales des agriculteurs familiaux du

Territoire de la Citoyenneté de la Vale do Rio Vermelho, à Goiás, Brasil

Recebido em 07/11/2014; revisado e aprovado em 22/03/2015; aceito em 27/07/2015

DOI: http:/ / dx.doi.org/10.20435/1518-70122016106

\begin{abstract}
Resumo: Este artigo avalia os efeitos do programa territorial PROINF nas relações sociais de agricultores familiares e também entre os membros do Conselho Municipal de Desenvolvimento Rural Sustentável (CMDRS). Os resultados mostram que os investimentos ocorridos em benefício direto dos agricultores resultaram em maior desenvolvimento local do que aqueles voltados às esferas intermediárias de mediação da política territorial.

Palavras-chave: Programa territorial. Agricultura familiar. Indicadores de rede.

Abstract: This paper assesses the influence of the territorial program PROINF in social relations of both family farmers and members of the Municipal Council for Sustainable Rural Development (CMDRS). The results reveal that the investments made for the direct benefit of family farmers have generated better effects on rural development than the ones aimed at intermediate levels of mediation of the territorial policy.

Key words: Territorial program. Family farming. Network indicators.

Résumé: Cet article évalue les effets du programme territorial PROINF dans les relations sociales des agriculteurs familiaux et également entre les membres du Conseil Municipal pour le Développement Rural Durable (CMDRS). Les résultats révèlent que les investissements directs pour agriculteurs familiaux ont généré de meilleurs effets sur le développement rural que ceux destinés aux intermédiaires de la médiation de la politique territoriale.

Mots-clés: Programe territorial. Agriculture familiale. Indicateurs de reseau.

Resúmen: Este artículo evalua los effectos del programa territorial PROINF en las relaciónes sociales de los campesinos y también entre los membros del Consejo Municipal de Desarrollo Rural Sostenible (CMDRS). Los resultados muestran que las inversiónes echas para el beneficio directo de los campesinos han generado mejor desarrollo local que los dirigidos hacia a las esferas intermediarias de mediación de la política territorial. Palabras clave: Programa territorial. Agricultura campesina. Indicadores de red.
\end{abstract}

\section{INTRODUÇÃO}

Este artigo apresenta uma avaliação sobre os efeitos da política territorial de desenvolvimento rural nas relações sociais dos agricultores familiares. A partir dos anos de 1980, o desenvolvimento territorial surgiu como política específica associando objetivos como desenvolvimento rural, redução da pobreza e conservação dos recursos naturais (FAVARETO, 2010; KAGEYAMA, 2008). Já nos anos de 1990, foram incorporados o protagonismo dos atores sociais e sua participação política, com o território como unidade de referência
(SCHNEIDER, 2004). A política associa o desenvolvimento às potencialidades locais e aos recursos e arranjos institucionais criados em territórios específicos (FUINI, 2014).

Nessa proposta, o território emerge como a nova unidade de referência para a atuação do Estado e das políticas públicas. Ganham destaque a descentralização das políticas públicas, a valorização da participação dos atores da sociedade civil, a redefinição do papel das instituições e a participação dos estados e do governo federal e, principalmente, das prefeituras locais com os atores da sociedade civil (ABRAMOVAY, 2001).

\footnotetext{
* Universidade Federal de Goiás (UFG), Goiânia, Goiás, Brasil.
} 
Nesse contexto, estão os Conselhos Municipais de Desenvolvimento Rural Sustentável (CMDRS), formados por instituições das entidades civis e públicas como instância de participação social de caráter municipal. Há também o colegiado territorial, que é composto por diferentes municípios e funciona como a instância de debate sobre o programa territorial, assumindo as atribuições de controle social, de mobilização e de articulação (LEITE; WESZ JÚNIOR, 2012).

Este estudo tem como objetivo geral avaliar o efeito de uma ação do programa territorial, o Programa Nacional da Agricultura Familiar (PRONAF) de infraestrutura que se transformou no Programa de Infraestrutura (PROINF), sobre a construção e o fortalecimento das relações sociais dos agricultores familiares e de suas instituições no Território da Cidadania do Vale do Rio Vermelho, em Goiás (TVRV). A ação do PROINF foi o financiamento, a fundo perdido, de tanques de leite para agricultores familiares do território, com vistas a atender a demanda local. Especificamente, o estudo busca analisar o efeito da política pública de desenvolvimento rural territorial nas relações sociais dos: do programa;

1. Agricultores familiares beneficiários

2. Membros dos Conselhos Municipais de Desenvolvimento Rural Sustentável, com enfoque nos atores que representam os grupos de agricultores beneficiados pelo programa.

\section{REFERENCIAL TEÓRICO}

Estudos sobre o território, e as políticas que incidem sobre ele, avaliam a vida social a partir das arenas ou dos campos (BOURDIEU, 2001). Segundo Bourdieu (2001), indivíduos ou grupos ocupam pontos e se redistribuem no território de acordo com modelos que podem ser aleatórios, regulares ou concentrados. Isso conduz a um sistema de tessituras, malhas, nós e redes que se imprimem dentro de um espaço (BOURDIEU, 2001).

Logo, no interior dessas tessituras, existem os atores que mantêm relações de acordo com sua posição e simbolizam os pontos denominados "nós". Esses pontos, à medida que podem se distanciar ou se aproximar, conforme o grau de comunicação estabele- cido, poderão constituir um sistema de rede (BOURDIEU, 2001).

Para Marteleto (2001), a análise de rede estabelece um novo paradigma para a pesquisa sobre a estrutura social, pois estuda como os comportamentos ou as opiniões dos indivíduos dependem das estruturas entre as quais eles se inserem. Schmitt (2011) destaca o uso da concepção de rede e das suas aplicações na análise e interpretação das políticas de desenvolvimento rural territorial, sob uma perspectiva relacional.

Granovetter (1973) também discute as redes interpessoais, a unidade de análise baseada nos laços sociais, que classifica como laços fortes (aqueles que os indivíduos mantêm por mais tempo, com maior intensidade emocional e mais trocas) e laços fracos (em que os indivíduos dependem menos uns dos outros). Esses laços podem ser a soma dos recursos decorrentes da existência de uma rede de relações de reconhecimento mútuo, institucionalizada em campos sociais, denominada de capital social (BOURDIEU, 1985).

O capital social é a soma dos recursos decorrentes da existência de uma rede de relações de reconhecimento mútuo, institucionalizada em campos sociais (BOURDIEU, 1985). Os recursos são empregados pelas pessoas a partir de uma estratégia de progresso dentro da hierarquia social do campo, prática resultante da interação entre o indivíduo e a estrutura (BOURDIEU, 1985). Cada campo social se caracteriza como um espaço no qual se manifestam as relações de poder, o que significa dizer que os campos sociais se estruturam a partir da distribuição desigual de um quantum social que determina a posição que cada agente específico ocupa em seu interior. Esse quantum representa o "capital social" (BOURDIEU, 1985).

Com essa concepção de rede e de capital social ligada à sociologia, os estudiosos têm analisado uma ampla gama de assuntos, mas, destes, três mereceram atenção especial por causa de sua relevância teórica. São eles: os efeitos da centralidade do agente sobre o comportamento, a identificação de subgrupos da rede e a natureza das relações entre as organizações (MIZRUCHI, 2006). Para efeito de estudo, neste trabalho serão discutidos os efeitos dos indicadores da centralidade e a relação com o capital social. 
Segundo Marteleto (2001), a centralidade de um ator significa a identificação da posição em que se encontra em relação às trocas e à comunicação na rede. Isso representa o número de relações que é colocado entre um ator e demais atores. O grau de centralidade é o número de atores ao qual um ator está diretamente ligado e divide-se em grau de entrada e grau de saída, dependendo da direção dos fluxos. O grau de saída é a soma das interações que os atores têm com os outros, e o grau de entrada é a soma das interações que os outros nós têm com o ator (ALVAREZ; GALLEGOS, 2006).

O grau de intermediação é a possibilidade que um nó tem para intermediar as comunicações entre os pares de nós e deve ter pelo menos um grau de entrada e de saída. Existem dois tipos de graus de intermediação: o grau de intermediação com números totais, ou seja, o número de pares de nós que um ator é capaz de ligar e o grau de intermediação normalizado, que indica o grau de intermediação em porcentagem (ALVAREZ; GALLEGOS, 2006).

O grau de proximidade é a capacidade de um nó de se ligar a todos os atores de uma rede, calculando as distâncias geodésicas de um ator para se ligar aos restantes. Para Marteleto (2001), a posição do ator será tão mais central quanto menor for o caminho a ser percorrido para alcançar os outros elos da rede. Isso mede, em última análise, a sua independência em relação ao controle dos outros.

A densidade é o quociente entre o número de ligações existentes pelo número de ligações possíveis em uma determinada rede e retrata a sua potencialidade em termos de fluxo de informações, ou seja, quanto maior a rede, mais intensa é a troca de informações e vice-versa. A densidade permitirá uma análise mais complexa das tessituras e dos nós dentro de uma rede (ALVAREZ; GALLEGOS, 2006). O enfoque deste estudo é a análise das relações ou das parcerias promovidas junto aos agricultores familiares, que podem influenciar o empoderamento dos atores envolvidos em um sistema de redes, como resultado de uma ação do PROINF.

\section{METODOLOGIA}

Este estudo pode ser classificado como uma pesquisa qualitativa e quantitativa ou método misto (CRESWELL, 2010). Para o levantamento de dados, utilizou a pesquisa documental, bibliográfica e os contatos diretos, ou seja, pesquisa de campo, por meio de entrevista estruturada (MARCONI; LAKATOS, 1985). O estudo compreendeu a análise de uma ação do PROINF, levada a cabo de 2003 a 2008, no Território da Cidadania do Vale do Rio Vermelho (TVRV), que abrange 16 municípios no Estado de Goiás.

A pesquisa de campo contemplou dois estudos de caso, sendo um com dois grupos de agricultores familiares de municípios diferentes, inseridos na cadeia produtiva do leite, a principal atividade produtiva apoiada pelo PROINF no TVRV. O outro, junto aos membros do Conselho Municipal de Desenvolvimento Rural Sustentável (CMDRS) nos municípios de Itaberaí e Goiás, destacando os atores que representam os grupos de agricultores familiares beneficiados por alguma ação do programa territorial.

Na primeira etapa, o questionário aplicado buscou coletar informações de antes e de depois da implantação do PROINF, com o objetivo de compreender as relações que foram constituídas por uma ação da política territorial na comunidade de agricultores familiares tradicionais e de assentamento da reforma agrária. O questionário analisou quais eram as pessoas que mais se relacionavam com o entrevistado para a comercialização do leite, antes do advento do PROINF. Depois da implantação do PROINF, o questionário identificou quais eram as pessoas com as quais o entrevistado possuía maior vínculo de relações para o uso dos bens de infraestrutura implantados pelo projeto, e qual a sua participação na organização e manutenção dos equipamentos (tanque de resfriamento de leite, por exemplo). Essas relações foram estudadas como categoria analítica organizacional por meio de indicadores gerais de rede que identificaram as interações existentes entre os diversos atores.

A segunda etapa do questionário local foi aplicada a todos os membros dos CMDRS dos municípios de Mossâmedes e Itaberaí. O questionário visou analisar, com maior ên- 
fase, as relações estabelecidas nas entidades representativas beneficiadas por alguma ação do PROINF, buscando entender se essas instituições estavam bem posicionadas nas trocas e comunicações, o que aumenta seu poder na rede, influenciando também a outra instância do programa territorial, que é o colegiado territorial.

Para a análise dos dados coletados através de questionários, foram feitas representações gráficas das redes usando os programas Ucinet 6.0 e Netdraw. O Ucinet é um programa para análise de redes, baseado em cálculos matemáticos que empregam a densidade e a centralidade como elementos de análise e que utilizam uma matriz a partir dos códigos utilizados pelos atores envolvidos, considerando o seu papel no interior das redes, ou por meio das relações e funções de análise de vários atributos de redes pré-definidas e automatizadas (ALVAREZ; GALLEGOS, 2006).

O Netdraw é um programa utilizado para ilustrar redes sociais e usa diferentes tipos de algoritmos para criar gráficos em duas e em três dimensões. Além dos indicadores de rede, será analisado o capital social presente nas diferentes redes constituídas.

\section{RESULTADOS}

\subsection{Estudo de Caso do Grupo de Agriculto- res Familiares do Município de Mossâme- des, GO e do Assentamento Dom Fernan- do Gomes, no Município de Itaberaí, GO}

A densidade da rede formada pelos agricultores familiares do município de Mossâmedes (Figuras 1 e 2) e do Projeto de Assentamento Dom Fernando Gomes, do município de Itaberaí (Figuras 3 e 4), na situação antes do PROINF foi baixa e, na situação após o PROINF, foi média. Isso significa que as redes estruturadas com o ator denominado leiteiro, ou atravessador, possuem alta dispersão, e os seus elos não estão bem conectados, diferente da situação após implantação do PROINF, quando a rede apresenta média dispersão, permitindo a conexão dos seus elos ou nós.

No indicador do grau de centralidade das duas redes formadas antes do PROINF, (Figuras 5 e 7 e tabelas 1 e 2), o resultado do grau de entrada (indegree) foi alto, pois todos os graus de entrada concentram-se na figura do leiteiro, ator central desta rede. O grau de centralidade foi muito baixo para o grau de saída (outdegree), demonstrando que não existe a formação de elos ou relações entre os atores. Nas redes formadas após o PROINF (Figuras 6 e 8 e tabelas 1 e 2), o indegree e o outdegree foram médios, indicando a existência de atores mais centrais do que outros.

No indicador do grau de intermediação antes do PROINF (Figuras 9 e 11 e tabelas 3 e 4 ), as duas redes apresentaram o valor nulo ou próximo a nulo, pois, para que tenha um grau de intermediação na rede, o nó deve ter pelo menos um grau de entrada e saída. $\mathrm{Na}$ rede formada após o PROINF (Figuras 10 e 12 e tabela 3 e 4), identificou-se a presença de atores-ponte, assim chamados por apresentarem a possibilidade do nó, ou seja, de poderem intermediar a comunicação entre os pares de nós. Segundo Marteleto (2001), um indivíduo é central em relação à informação quando, por seu posicionamento, recebe informações vindas da maior parte do ambiente da rede, tornando-se uma fonte estratégica.

$\mathrm{O}$ indicador do grau de proximidade, para análise das duas redes antes do PROINF (Figuras 13 e 15 e tabelas 5 e 6), aponta o atravessador com o maior grau de proximidade de entrada. A rede formada depois do PROINF (Figuras 14 e 16 e tabelas 5 e 6) demonstra a presença de agricultores com maior grau de proximidade, de entrada e de saída, permitindo a independência destes em relação ao controle dos outros.

Esse modelo de rede, considerada de elos fortes, robustece os seus atores e promove a competitividade na gestão social dos empreendimentos beneficiados. 


\section{Figuras Referentes aos Indicadores de Rede demonstrando as Relações Promovidas entre os Agricultores Familiares e suas Organizações pela Implantação da Política Territorial}

Figura 1 - Densidade antes do PROINF, Mossâmedes

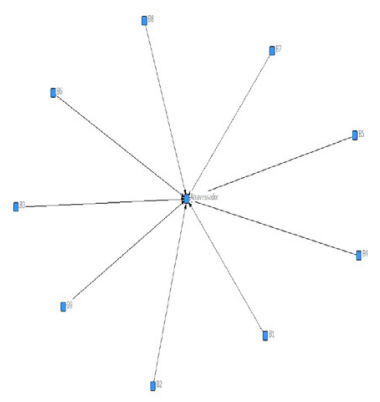

Figura 5 - Grau de centralidade antes do PROINF, Mossâmedes

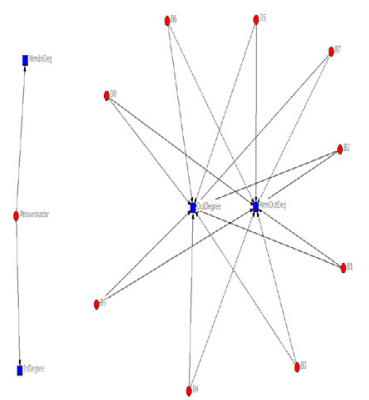

Figura 9 - Grau de intermediação antes do PROINF, Mossâmedes

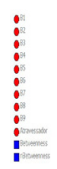

Figura 13 - Grau de proximidade antes do PROINF, Mossâmedes

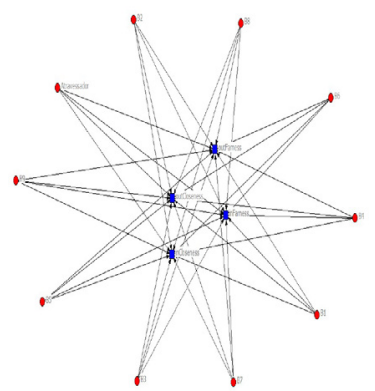

Figura 2 - Densidade depois do PROINF, Mossâmedes

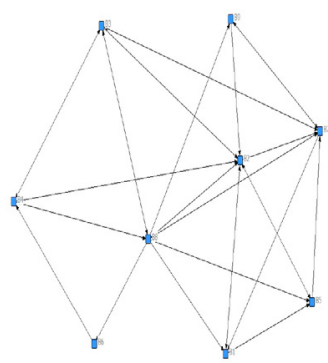

Figura 6 - Grau de centralidade depois do PROINF, Mossâmedes

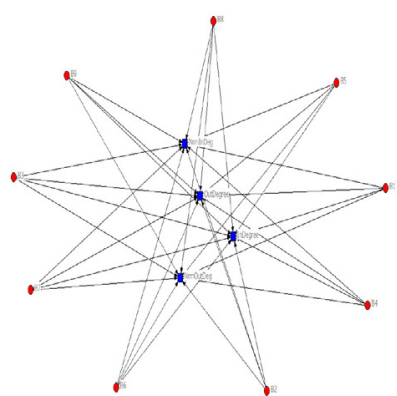

Figura 10 - Grau de intermediação depois do PROINF, Mossâmedes

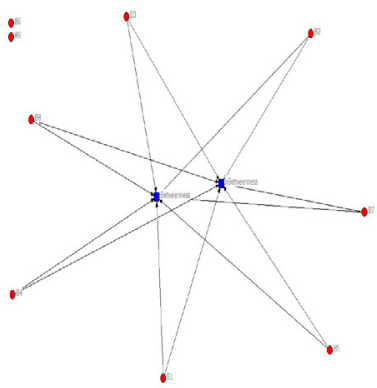

Figura 14 - Grau de proximidade depois do PROINF, Mossâmedes

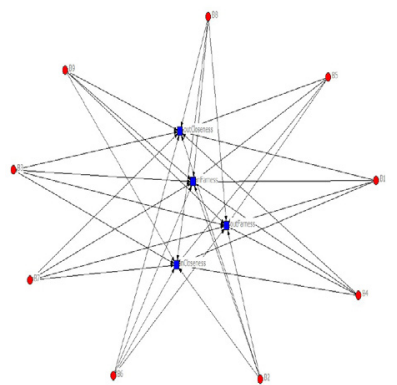

Figura 3 - Densidade antes do Figura 4 - Densidade depois PROINF, Itaberaí do PROINF, Itabera
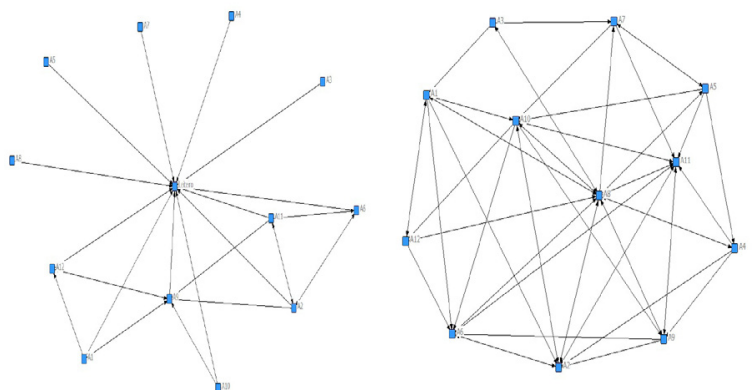

Figura 7 - Grau de centralidade antes do PROINF, Itaberaí

Figura 8 - Grau de centralidade depois do PROINF, Itaberaî
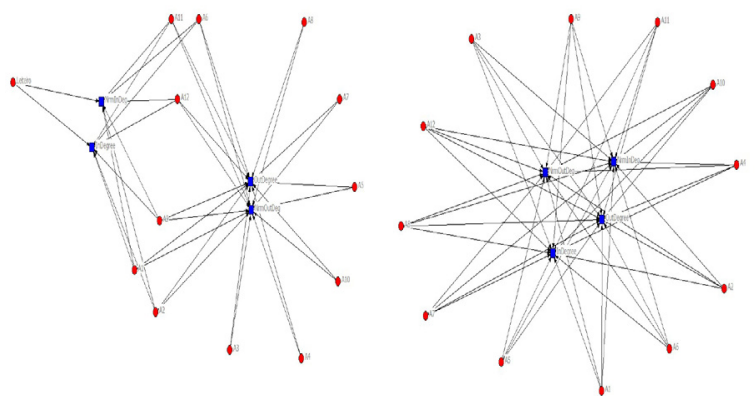

Figura 11 - Grau de intermediação antes do PROINF, Itaberaí

Figura 12 - Grau de intermediação depois do PROINF, Itaberaî
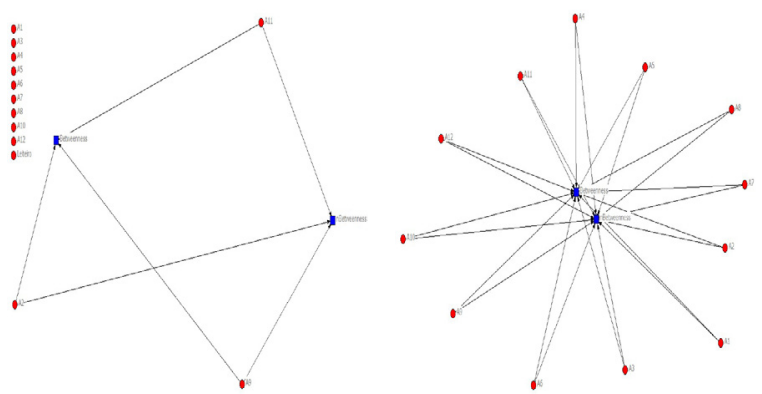

Figura 15 - Grau de proximidade antes do PROINF, Itaberaí

Figura 16 - Grau De proximidade depois do PROINF, Itaberaí
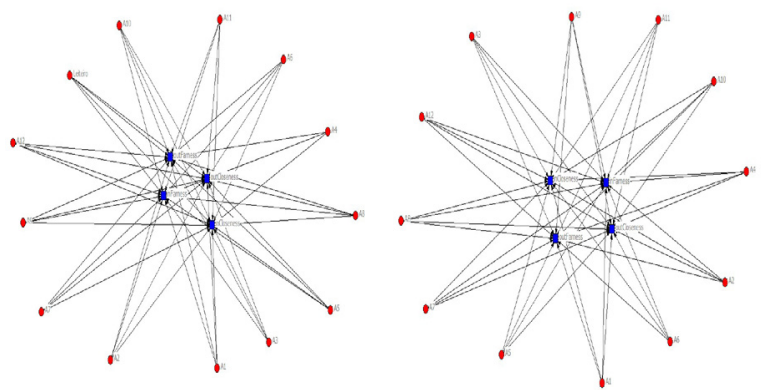
Tabelas Referentes aos Resultados dos Indicadores de Rede das Relações Promovidas entre os Agricultores Familiares e suas Organizações

Tabela 1 - Resultado estatístico da centralidade antes e depois do PROINF para a rede de Mossâmedes

\begin{tabular}{cccccc}
\hline \multirow{2}{*}{$N^{o}$} & ESTATÍSTICAS DESCRITIVAS & \multicolumn{2}{c}{ GRAU DE SAÍDA } & \multicolumn{2}{c}{ GRAU DE ENTRADA } \\
& DA REDE & \multicolumn{2}{c}{ NORMALIZADO } & \multicolumn{2}{c}{ NORMALIZADO } \\
& & ANTES & DEPOIS & ANTES & DEPOIS \\
1 & Média & 10,00 & 45,83 & 10,00 & 45,83 \\
2 & Desvio padrão & 3,33 & 25,00 & 30,00 & 20,41 \\
3 & Soma & 100,00 & 412,50 & 100,00 & 412,50 \\
4 & Variância & 11,11 & 625,00 & 900,00 & 416,66 \\
5 & Mínimo & 0,00 & 12,50 & 0,00 & 12,50 \\
6 & Máximo & 11,11 & 100,00 & 100,00 & 87,50 \\
\hline
\end{tabular}

Tabela 2 - Resultado estatístico da centralidade antes e depois do PROINF para a rede de Itaberaí

\begin{tabular}{cccccc}
\hline \multirow{2}{*}{$N^{\circ}$} & ESTATÍ́STICAS & \multicolumn{2}{c}{ GRAU DE SAÍDA } & \multicolumn{2}{c}{ GRAU DE ENTRADA } \\
& DESCRITIVAS DA REDE & \multicolumn{2}{c}{ NORMALIZADO } & \multicolumn{2}{c}{ NORMALIZADO } \\
& & ANTES & DEPOIS & ANTES & DEPOIS \\
1 & Média & 16,66 & 41,66 & 16,66 & 41,66 \\
2 & Desvio Padrão & 10,33 & 19,09 & 26,75 & 21,14 \\
3 & Soma & 216,66 & 500,00 & 216,66 & 500,00 \\
4 & Variância & 106,83 & 364,44 & 715,81 & 447,08 \\
5 & Mínimo & 0,00 & 27,27 & 0,00 & 18,18 \\
6 & Máximo & 33,33 & 100,00 & 100,00 & 72,72 \\
\hline
\end{tabular}

Tabela 3 - Resultado estatístico do grau de intermediação depois do PROINF para a rede de Mossâmedes

\begin{tabular}{cccc}
\hline $\mathrm{N}^{\circ}$ & ESTATÍSTICAS & GRAU DE & GRAU DE INTERMEDIAÇÃO \\
1 & DESCRITIVAS & INTERMEDIAÇÃO DEPOIS & NORMALIZADO \% DEPOIS \\
2 & Média & 5,33 & 9,52 \\
3 & Desvio padrão & 5,90 & 10,53 \\
4 & Soma & 48,00 & 85,71 \\
5 & Variância & 34,82 & 111,04 \\
6 & Mínimo & 0,00 & 0,00 \\
\hline
\end{tabular}

Tabela 4 - Resultado estatístico do grau de intermediação antes e depois do PROINF para a rede de Itaberaí

\begin{tabular}{|c|c|c|c|c|c|}
\hline $\mathrm{N}^{\mathrm{o}}$ & $\begin{array}{l}\text { ESTATÍSTICAS } \\
\text { DESCRITIVAS }\end{array}$ & $\begin{array}{c}\text { GRAU DE } \\
\text { INTERMEDIAÇÃO } \\
\text { ANTES }\end{array}$ & $\begin{array}{l}\text { GRAU DE INTERME- } \\
\text { DIAÇÃO NORMALI- } \\
\text { ZADO \% ANTES }\end{array}$ & $\begin{array}{l}\text { GRAU DE IN- } \\
\text { TERMEDIA- } \\
\text { ÇÃO DEPOIS }\end{array}$ & $\begin{array}{l}\text { GRAU DE INTERME- } \\
\text { DIAÇÃO NORMALI- } \\
\text { ZADO \% DEPOIS }\end{array}$ \\
\hline 1 & Média & 0,92 & 0,69 & 6,91 & 6,28 \\
\hline 2 & Desvio Padrão & 2,39 & 1,81 & 13,30 & 12,09 \\
\hline 3 & Soma & 12,00 & 9,09 & 83,00 & 75,45 \\
\hline 4 & Variância & 5,72 & 3,28 & 177,12 & 146,38 \\
\hline 5 & Mínimo & 0,00 & 0,00 & 0,95 & 0,86 \\
\hline 6 & Máximo & 9,00 & 6,81 & 50,30 & 45,72 \\
\hline
\end{tabular}

Tabela 5 - Resultado estatístico do grau de proximidade antes e depois do PROINF para a rede de Mossâmedes

\begin{tabular}{cccccc}
\hline & ESTATÍSTICAS & GRAU DE PRO- & GRAU DE PRO- & GRAU DE PROXI- & GRAU DE PRO- \\
$N^{0}$ & DESCRITIVAS & XIMIDADE DE & XIMIDADE DE & MIDADE DE EN- & XIMIDADE DE \\
& DA REDE & ENRADA ANTES & SAIIDA ANTES & TRADA DEPOIS & SAÍDA DEPOIS \\
& MOSÂAMDES & MOSSÂMEDES & MOSSÂMEDES & MOSSÂMEDES \\
1 & Média & 19,00 & 11,00 & 62,12 & 63,70 \\
2 & Desvio Padrão & 27,00 & 0,33 & 11,96 & 16,28 \\
3 & Soma & 190,00 & 110,00 & 559,15 & 573,30 \\
4 & Variância & 729,00 & 0,11 & 143,08 & 265,31 \\
5 & Mínimo & 10,00 & 10,00 & 44,44 & 42,10 \\
6 & Máximo & 100,00 & 11,11 & 88,88 & 100,00 \\
\hline
\end{tabular}


Tabela 6 - Resultado estatístico do grau de proximidade antes e depois do PROINF para a rede de Itaberaí

\begin{tabular}{cccccc}
\hline & ESTATÍSTICAS & GRAU DE PRO- & GRAU DE PRO- & GRAU DE PRO- & GRAU DE PRO- \\
$\mathrm{N}^{\mathrm{O}}$ & DESCRITIVAS & XIMIDADE DE & XIMIDADE DE & XIMIDADE DE & XIMIDADE DE \\
& DA REDE & ITABERAII & SAITA ANTES & ENTRADA DE- & SAÍDA DEPOIS \\
& & 16,48 & 10,12 & 63,00 & 63,10 \\
1 & Média & 24,22 & 2,20 & 10,31 & 12,08 \\
2 & Desvio Padrão & 214,36 & 131,57 & 756,08 & 757,30 \\
3 & Soma & 586,70 & 4,86 & 106,35 & 146,13 \\
4 & Variância & 7,69 & 7,69 & 52,38 & 47,82 \\
5 & Mínimo & 100,00 & 13,95 & 78,57 & 100,00 \\
6 & Máximo & & & & \\
\hline
\end{tabular}

\subsection{Estudo de Caso dos Membros do Con- selho Municipal de Desenvolvimento Ru- ral Sustentável (CMDRS) dos Municípios de Itaberaí e Mossâmedes}

A análise dos resultados dos indicadores gerais da rede formada pelos membros do CMDRS do município de Itaberaí (Figura 17) e de Mossâmedes (Figura 18) concluiu que a densidade da rede foi baixa. Essas redes apresentaram alta dispersão, e os seus elos não estão bem conectados, apresentando atores isolados, que não conseguem ligar-se aos vários nós.

No indicador do grau de centralidade das redes do CMDRS de Mossâmedes (Figura 20 e tabela 7) e Itaberaí (Figura 19 e tabela 8), o resultado do indegree foi alto, pois todos os graus de entrada concentram-se em instituições como o Sindicato dos Trabalhadores Rurais (STR) e a EMATER, atores centrais desta rede. O outdegree foi baixo para a rede formada pelo ator central, a EMATER, membro do CMDRS de (Mossâmedes), demonstrando que existe pouca formação de elos ou relações entre os atores; e, para a rede formada pelo ator central, oSTR de Itaberaí, o outdegree foi médio.

No indicador do grau de intermediação, as duas redes, de Mossâmedes (Figura 22 e tabela 9) e de Itaberaí (Figura 21 e tabela 10), apresentaram apenas dois atores-ponte, com valores totais capazes de intermediar a comunicação entre os pares de nós. Na rede do CMDRS de Mossâmedes, quase $90 \%$ dos atores estão isolados.

No indicador do grau de proximidade de entrada da rede dos membros do CMDRS de Mossâmedes (Figura 24 e tabela 11) e de Itaberaí (Figura 23 e tabela 12) foram identificados atores com valores totais altos, mas, no grau de proximidade de saída, verificaram-se valores baixos, revelando uma rede na qual os elos e os nós não estão bem conectados. Os indicadores gerais de análise de rede dos dois estudos de caso apresentaram resultados bem próximos na densidade, no grau de centralidade e no grau de proximidade, destacando-se, nessas duas redes, apenas um ou dois atores que possuem altos valores totais ou normalizados. Os demais atores ou membros do conselho apresentam valores baixos, ou estão, em alguns casos, isolados.

Isso indica que os nós e os elos das duas redes não se comunicam e a rede possui baixa conectividade entre os atores, tornando a interação ou a relação entre os membros dos CMDRS fracas ou frágeis. Nas relações entre os membros do CMDRS, foi analisada também a instituição que possuía maior interação com os membros do conselho para a discussão sobre as atividades do grupo. No município de Itaberaí, os dados indicaram o SRT, e em Mossâmedes, a EMATER.

Essas instituições possuem representantes que atuam nas atividades desenvolvidas pelo conselho. Sobre a influência dos extensionistas no CMDRS, Abramovay (2001) observa que a rede nacional de extensionistas foi o corpo orgânico no qual se apoiou fundamentalmente a proliferação dos conselhos municipais de desenvolvimento rural. A extensão, junto com o movimento sindical de trabalhadores rurais, foi uma peça decisiva na montagem do PRONAF (ABRAMOVAY, 2001).

No que se refere às relações ou interações dos membros do CMDRS com o colegiado territorial, os dados indicam, no município de Itaberaí, o membro do STR e, em Mossâmedes, a EMATER, que se destacou no CMDRS do município e tem influência também nas relações com o colegiado territorial, pois possui representação junto a ele. 
Figuras Referentes aos Indicadores de Rede demonstrando as Relações entre os Membros do Conselho Municipal de Desenvolvimento Rural Sustentável e sua Interação com o Colegiado Territorial

Figura 17 - Densidade do CMDRS de ITABERAÍ

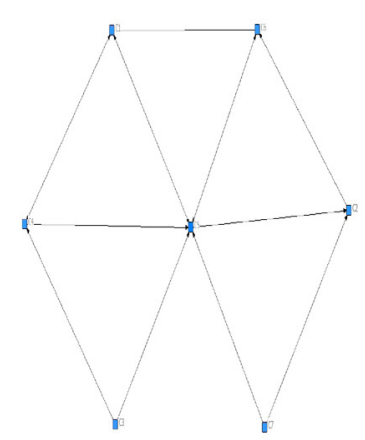

Figura 21 - Grau de Intermediação do CMDRS de ITABERAÍ

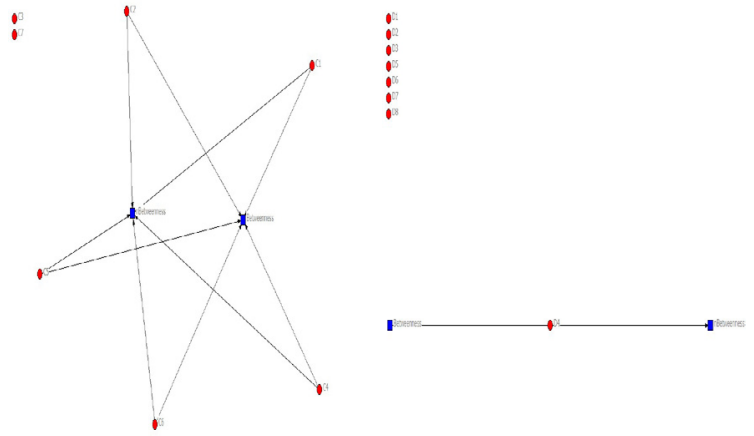

Figura 18 - Densidade do CMDRS de MOSSÂMEDES

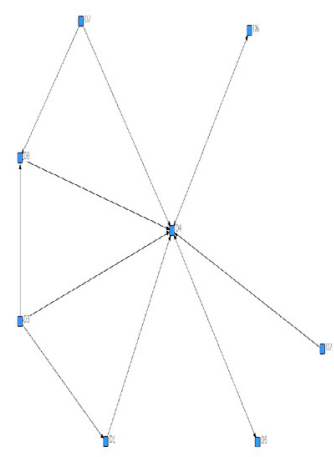

Figura 22 - Grau de Intermediação do CMDRS de MOSSÂMEDES
Figura 19 - Grau de centrali- , Figura 20 - Grau de centralidade dade do CMDRS de TABERAÍ do CMDRS de MOSSÂMEDES
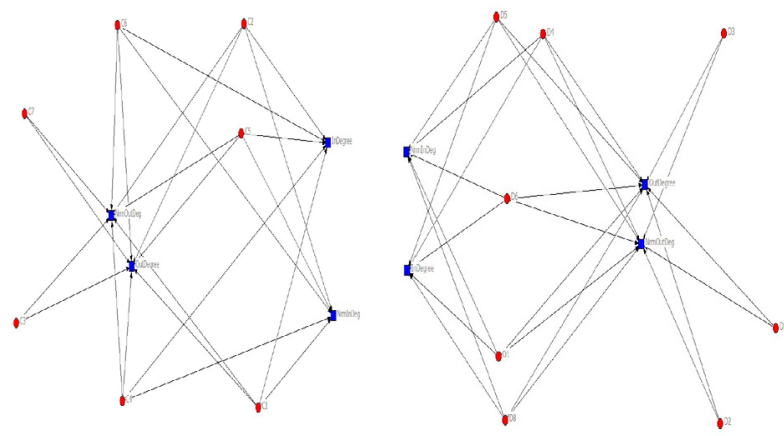

Figura 23 - Grau de proximida- Figura 24- Grau de proximidade de do CMDRS de ITABERAÍ do CMDRS de MOSSÂMEDES

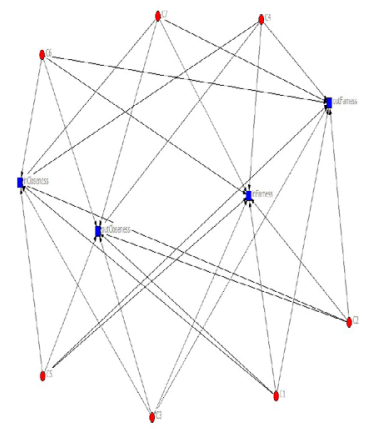

Tabelas Referentes aos Resultados dos Indicadores de Rede das Relações entre os Membros do Conselho Municipal de Desenvolvimento Rural Sustentável

Tabela 7 - Resultado estatístico da centralidade para a rede formada pelos membros do CMDRS de Mossâmedes

\begin{tabular}{cccc}
\hline$N^{\circ}$ & ESTÁTISTICAS & GRAU DE SAÍDA & GRAU DE ENTRADA \\
1 & DESCRITIVAS & NORMALIZADO & NORMALIZADO \\
2 & Média & 21,42 & 21,42 \\
3 & Desvio Padrão & 10,10 & 31,13 \\
4 & Soma & 171,42 & 171,42 \\
5 & Variância & 102,04 & 969,38 \\
6 & Mínimo & 14,28 & 0,00 \\
\hline
\end{tabular}

Tabela 8 - Resultado estatístico da centralidade para a rede formada pelos membros do CMDRS de Itaberaí

\begin{tabular}{cccc}
\hline $\mathrm{N}^{\mathrm{O}}$ & ESTÁTISTICAS & GRAU DE SAÍDA & GRAU DE ENTRADA \\
1 & DESCRITIVAS & NORMALIZADO & NORMALIZADO \\
2 & Média & 38,09 & 38,09 \\
3 & Desvio Padrão & 11,66 & 31,76 \\
4 & Soma & 266,66 & 266,66 \\
5 & Variância & 136,05 & 1009,07 \\
6 & Mínimo & 33,33 & 0,00 \\
\hline
\end{tabular}


Tabela 9 - Resultado estatístico do grau de intermediação da rede formada pelos membros do CMDRS de Mossâmedes

\begin{tabular}{|c|c|c|c|}
\hline $\mathrm{N}^{\mathrm{o}}$ & & $\begin{array}{l}\text { GRAU DE INTERMEDIAÇÃO DO } \\
\text { CMDRS }\end{array}$ & $\begin{array}{l}\text { GRAU DE INTERMEDIAÇÃO } \\
\text { NORMALIZADO \% DO CMDRS }\end{array}$ \\
\hline 1 & Média & 1,50 & 3,57 \\
\hline 2 & Desvio Padrão & 3,96 & 9,44 \\
\hline 3 & Soma & 12,00 & 28,57 \\
\hline 4 & Variância & 15,75 & 89,28 \\
\hline 5 & Mínimo & 0,00 & 0,00 \\
\hline 6 & Máximo & 12,00 & 28,57 \\
\hline
\end{tabular}

Tabela 10 - Resultado estatístico do grau de intermediação da rede formada pelos membros do CMDRS de Itaberaí

\begin{tabular}{cccc}
\hline $\mathrm{N}^{\mathrm{o}}$ & ESTATÍSTICAS & GRAU DE INTERMEDIAÇÃO & GRAU DE INTERMEDIAÇ̃̃O \\
& DESCRITIVAS & DO CMDRS & NORMALIZADO \% DO CMDRS \\
1 & Média & 2,00 & 6,66 \\
2 & Desvio Padrão & 4,08 & 13,62 \\
3 & Soma & 14,00 & 46,66 \\
4 & Variância & 16,71 & 185,71 \\
5 & Mínimo & 0,00 & 0,00 \\
6 & Máximo & 12,00 & 40,00 \\
\hline
\end{tabular}

Tabela 11 - Resultado estatístico do grau de proximidade da rede formada pelos membros do CMDRS de Mossâmedes

\begin{tabular}{cccc}
\hline & GRAU DE PROXIMIDADE & GRAU DE PROXIMIDADE DE \\
& ESTATÍSTICAS & DEICANA DOS MEMBROS DO \\
& DESCRITIVAS & MEMBROS DO CMDRS & CMDRS \\
1 & Média & 43,51 & 19,96 \\
2 & Desvio Padrão & 30,03 & 4,50 \\
3 & Soma & 276,14 & 159,75 \\
4 & Variância & 902,18 & 20,28 \\
5 & Mínimo & 12,50 & 16,27 \\
6 & Máximo & 100,00 & 30,43 \\
\hline
\end{tabular}

Tabela 12 - Resultado estatístico do grau de proximidade da rede formada pelos membros do CMDRS de Itaberaí

\begin{tabular}{cccc}
\hline & GRAU DE PROXIMIDADE & GRAU DE PROXIMIDADE DE \\
$N^{o}$ & ESTATÍSTICAS & DEÍDA DOS MEMBROS DO \\
& DESCRITIVAS & MEMBRTRADA DOS & CMDRS \\
1 & Média & 54,55 & 33,33 \\
2 & Desvio Padrão & 28,43 & 4,36 \\
3 & Soma & 381,90 & 233,33 \\
4 & Variância & 808,73 & 19,04 \\
5 & Mínimo & 14,28 & 30,00 \\
6 & Máximo & 100,00 & 40,00 \\
\hline
\end{tabular}

\section{DISCUSSÃO}

Apesar de terem ocorrido inegáveis avanços no campo, ainda são poucos os programas institucionais para a promoção do desenvolvimento sustentável para os atores que ali residem e trabalham para garantir a sua sobrevivência e a geração de renda. Por isso, o Programa Territorial, por meio da política do PROINF, possui grande importância ao atender às demandas de infraestrutura necessária para o meio rural. Como principal potencial que caracteriza essa política pública, está o fato de ela poder ser direcionada para atender diretamente os beneficiários finais, que são os agricultores, possibilitando gran- 
de impacto em favor do desenvolvimento rural dos moradores do campo (FUINI, 2014; FAVARETO, 2010; KAGEYAMA, 2008).

Este estudo permitiu compreender o efeito de uma política pública do programa territorial, o Programa de Infraestrutura (PROINF), por meio da análise de uma ação do Programa, o financiamento a fundo perdido de tanques de resfriamento de leite a agricultores familiares. Os indicadores gerais de análise de rede dos dois grupos de agricultores familiares apresentaram resultados bem próximos, na rede formada antes e depois do PROINF, na densidade, no grau de centralidade, na intermediação e na proximidade. Os resultados demonstram que a rede formada antes do PROINF tem baixa conectividade entre os atores, e o atravessador torna-se o elo ou o ator central, mas não possui capacidade de intermediar as interações entre os pares de nós e gera a dependência de todos os atores em relação a ele.

A rede formada após o PROINF que financiou tanques de resfriamento de leite para os agricultores não possui o atravessador. Ela é formada apenas por agricultores e apresentou média conectividade entre os atores, podendo-se observar também que os próprios agricultores são os atores centrais no grau de centralidade, proximidade e intermediação, fortalecendo as relações ou elos da rede e permitindo a sua independência em relação ao controle dos outros. Segundo Granovetter (1973), essa rede é considerada de elos fortes, pois possui atores centrais (agricultores familiares) em todos os indicadores de rede.

Outro dado relevante levantado na pesquisa de campo, tanto dos agricultores de Mossâmedes, como dos de Itaberaí, foi sobre o mercado para a comercialização dos produtos. Antes da chegada do PROINF, a comercialização era feita com empresas de caráter local ou municipal. Após a chegada do programa, os agricultores conseguiram viabilizar a entrega do leite para empresas regionais, ou seja, tiveram acesso a novos mercados fora do círculo de relações sociais locais. Esses dados reafirmam o objetivo da política territorial ao promover o acesso dos agricultores familiares a novos atores (empresas regionais).

As mudanças ocorridas nesses grupos de agricultores foram capazes de fortalecer a formação de capital social no campo. Algumas características específicas desses grupos influenciam os aspectos culturais, econômicos, políticos e sociais, que, na perspectiva de Bourdieu (1985), são os recursos que interagem com os atores e formam as redes de relações de poder nos campos sociais e que determinam a posição desses atores em uma rede.

A soma desses recursos mais a rede de relações nos campos sociais formam o chamado quantum, que é o capital social (BOURDIEU, 1985). Assim, as redes formadas por meio da ação do PROINF fomentaram a formação do quantum e o fortalecimento das relações entre os próprios agricultores familiares, que constituíram redes de elos fortes, que, influenciadas pelos recursos disponíveis nos campos sociais, determinaram as posições de cada ator no grupo.

Com isso, o Programa Territorial, por meio de uma ação ligada ao PROINF, promoveu o estímulo ao empoderamento de redes dos atores locais ou o fortalecimento do capital social, que, segundo Favareto (2010) e Delgado e Leite (2011), são elementos estratégicos para a concepção do desenvolvimento territorial, processo no qual o social se integra ao econômico (MATOS; BASTOS, 2014).

$\mathrm{Na}$ segunda análise sobre as relações entre os membros do CMDRS, destacando-se a interação dos atores que são membros representantes dos grupos de agricultores familiares beneficiários do PROINF, a rede apresentou baixa densidade, com elos pouco conectados e atores isolados, que não conseguiram ligar-se aos vários nós, tornando a interação ou a relação entre os membros fraca ou frágil. Assim, essa rede, constituída pelos membros do CMDRS, apresentou resultados baixos na densidade, no grau de centralidade, no grau de intermediação e no grau de proximidade.

Os atores que se destacaram nos graus de centralidade, proximidade e intermediação, e que também fazem a interação do grupo com o colegiado territorial, são o representante do Sindicato dos Trabalhadores Rurais (Itaberaí) e a EMATER (Mossâmedes).

Este trabalho contribui para mostrar, por meio da análise da interação social de realidades locais distintas, que a implantação de uma ação da política pública, no 
caso o PROINF, produziu efeito positivo nas relações sociais dos agricultores familiares beneficiados, mas, no que tange aos CMDRS, existe ainda grande fragilidade dessas relações.

\section{CONSIDERAÇÕES FINAIS}

O resultado deste trabalho mostra que o Programa Territorial, ao proporcionar o acesso a pequenos projetos de bens ou equipamentos diretos aos beneficiários, promoveu um impacto nas relações sociais e no empoderamento dos agricultores familiares. Por isso, alguns dos objetivos centrais da concepção territorial e de desenvolvimento local foram alcançados por meio das ações do PROINF. Os dados revelam que pequenos investimentos da política de desenvolvimento local e territorial direcionados ao público-fim (os agricultores) tiveram efeito positivo de empoderamento dos atores locais.

Em relação ao resultado das redes formadas pelos membros do CMDRS, os atores representantes dos grupos de agricultores familiares beneficiários do PROINF inseridos em redes de elos fortes em seus grupos de produção não conseguiram transferir o seu poder para as relações junto aos membros do CMDRS. Nessa rede, estruturada pelos membros do conselho, os dados indicam que são necessárias mudanças na estruturação, composição e funcionamento dos CMDRS que hoje possuem apenas poder consultivo - opina e emite pareceres -, não podendo deliberar.

Isso faz com que seus membros não se sintam protagonistas para propor mudanças e, por isso, não conseguem interferir nas questões ligadas ao desenvolvimento local. As redes estruturadas nos CMDRS não conseguiram atingir os objetivos do programa territorial e não promoveram o empoderamento de seus membros. Como lição para o desenvolvimento local, pode-se dizer que investimentos em benefício direto dos agricultores surtiram mais efeito do que aqueles voltados às esferas intermediárias de mediação da política territorial como os CMDRS.

\section{REFERÊNCIAS}

ABRAMOVAY, Ricardo. O capital social dos territórios: repensando o desenvolvimento rural. Economia Aplicada, São Paulo, v. 4, n. 2, p. 379-397, abr./jun. 2000.

Conselhos além dos limites. Estudos Avançados, São Paulo, v. 15, n. 43, p. 121-137, dez. 2001.

. Para uma teoria dos estudos territoriais. In: ORTEGA, Antonio Cesar. (Org.). Desenvolvimento territorial, segurança alimentar e economia solidária. Campinas, SP: Alínea, p. 20-36, 2007.

ALVAREZ, Velazquez O. Alejandro; GALLEGOS, Aguilar Norman. Manual introdutório à análise de redes sociais. Tradução Maria Luisa Aires México: Universidade Autônoma do Estado do México, 2006.

BORDIEU, Pierre. Contrafogos 2: por um movimento social europeu. Tradução André Telles. Rio de Janeiro: Jorge Zahar, 2001.

. The forms of capital. In: RICHARDSON, J. (Comp.). Handbook of theory and research for the sociology of education. New York: Greenwood, 1985.

CRESWELL, John W. Projeto de pesquisa: métodos qualitativo, quantitativo e misto. Tradução Magna Lopes. Porto Alegre, RS: Artmed, 2010.

DELGADO, Nelson Giordano; LEITE; Sérgio Pereira. Políticas de desenvolvimento territorial no meio rural brasileiro: novas institucionalidades e protagonismo dos atores. Dados - Revista de Ciências Sociais, Rio de Janeiro, v. 54, n. 2, p. 431-473, 2011.

FAVARETO, Arilson. A abordagem territorial do desenvolvimento rural; mudança institucional ou "inovação por adição". Estudos Avançados, São Paulo, v. 24, n. 68, p. 299-319, 2010.

FUINI, Lucas Labigalini. A territorialização do desenvolvimento: construindo uma proposta metodológica. Interações, Campo Grande, MS, v. 15, n. 1, p. 21-34, ja./ jun. 2014.

GRANOVATTER, Mark. The strength of weak ties. American Journal of Sociology, v. 78, n. 6, p. 1360-1380, 1973.

LEITE, Sérgio Pereira; WESZ JÚNIOR, Valdemar João. Um estudo sobre o financiamento da política de desenvolvimento territorial no meio rural brasileiro. Revista Economia Sociologia Rural, Piracicaba, SP, v. 50, n. 4, p. 645-666, 2012.

KAGEYAMA, Angela. Desenvolvimento rural: conceitos e aplicação ao caso brasileiro. Porto Alegre, RS: UFRGS, 2008.

MARCONI, Marina de Andrade; LAKATOS, Eva Maria. Fundamentos de metodologia científica. São Paulo: Atlas, 1985.

MARTELETO, Regina Maria. Análise de redes sociais: aplicação nos estudos de transferência da informação. Ciência da Informação, Brasília, v. 30, p. 71-81, 2001.

MATOS, Fátima Regina Ney; BASTOS, Adriana Teixeira; MACHADO, Diego de Queiroz. Desenvolvimento local no agreste pernambucano: uma "utopia possível". Revista Interação, Campo Grande, MS, v. 15, n. 1, p. 147157, jan./jun. 2014. 
MIZRUCHI, Mark S. Análise de redes sociais: avanços recentes e controvérsias atuais. RAE - Revista de Administração de Empresas, Rio de Janeiro, v. 46, n. 3, p. 72-86, jul./set. 2006.

SCHMITT, Cláudia Job. Redes, atores e desenvolvimento rural: perspectivas na construção de uma abordagem relacional. Sociologias, Porto Alegre, RS, ano 13, n. 27, p. 82-112, maio/ago. 2011.

SHNEIDER, Sergio. A abordagem territorial do desenvolvimento rural e suas articulações externas. Sociologias, Porto Alegre, RS, ano 6, n. 11, p. 88-125, jan./ jun. 2004. 